\title{
Coronary angiography in patients after cardiac arrest without ST-elevation myocardial infarction
}

\section{A retrospective cohort analysis}

\author{
Matthias Mueller · Daniela Dziekan · Michael Poppe (D) - Christian Clodi · Christoph Schriefl · Martin Hofbauer • \\ Christian Roth · Alexander Nuernberger · Michael Holzer · Christoph Weiser
}

Received: 4 November 2020 / Accepted: 23 May 2021 / Published online: 30 June 2021

(C) The Author(s) 2021

\begin{abstract}
Summary
Background Coronary artery disease (CAD) is the most common cause of sudden cardiac arrest (SCA). Although coronary angiography (CAG) should be performed also in the absence of ST-elevation (STE) after sustained return of spontaneous circulation (ROSC), this recommendation is not well implemented in daily routine.

Methods A retrospective database analysis was conducted in a tertiary care center between January 2005 and December 2014. We included all SCA patients aged $\geq 18$ years with presumed cardiac cause and sustained ROSC in the absence of STE at hospital admission. The rate and timing of CAG were defined as the primary endpoints. As secondary endpoints, the reasons pro and contra CAG were analyzed. Furthermore, we observed if the signs and symptoms used for decision making occurred more often in patients with treatable CAD.

Results We included 645 (53.6\%) of the 1203 screened patients, CAG was performed in $343(53.2 \%)$ patients with a diagnosis of occlusive CAD in $214(62.4 \%)$ patients. Of these, $151(71.0 \%)$ patients had occlusive CAD treated with coronary intervention, thrombus
\end{abstract}

\footnotetext{
M. Mueller, MD · D. Dziekan, MD · M. Poppe, MD (凶) · C. Clodi, MD · C. Schriefl, MD · A. Nuernberger, MD . M. Holzer, MD · C. Weiser, MD

Department of Emergency Medicine, Medical University of Vienna, Waehringer Guertel 18-20/6D, 1090 Vienna, Austria michael.poppe@meduniwien.ac.at
}

\section{Hofbauer}

Vienna University of Technology, Karlsplatz 13, 1040 Vienna, Austria

\section{Roth, MD}

Department of Medicine II, Division of Cardiology, Medical University of Vienna, Waehringer Guertel 18-20/6L, 1090 Vienna, Austria aspiration, or coronary artery bypass grafting. In an adjusted binomial logistic regression analysis, age $\geq 70$ years, female sex, non-shockable rhythms, and cardiomyopathy were associated with withholding of CAG. In patients diagnosed and treated with occlusive CAD, initially shockable rhythms, previously diagnosed $\mathrm{CAD}$, hypertension, and smoking were found more often.

Conclusion Although selection bias is unavoidable due to the retrospective design of this study, a high proportion of the examined patients had occlusive CAD. The criteria used for patient selection may be suboptimal.

Keywords Resuscitation · Postresuscitation care · Percutaneous coronary intervention · NSTEMI · Catheterization

\section{Introduction}

Sudden cardiac arrest (SCA) is one of the leading causes of death, affecting up to 700,000 individuals in Europe every year [1]. Coronary artery disease (CAD) is the underlying problem in $75 \%$ of patients with presumed cardiac cause [2]. Therefore, immediate coronary angiography (CAG) and percutaneous coronary intervention (PCI), if appropriate, should be a substantial part of standardized postresuscitation care [3]. Based on observational studies, emergent CAG for resuscitated patients with ST-elevation (STE) myocardial infarction is recommended and leads to both increased survival and improved neurological outcomes [4].

The approach concerning CAG for patients after SCA in the absence of STE remains unclear because of conflicting data. While some studies have associated early CAG \pm PCI with decreased mortality [5, 6], other studies could not show this effect [7-10]. 
Therefore, the European Resuscitation Council recommends providing CAG to those with the highest risk of coronary lesions [3].

However, identifying patients with the highest risk of occlusive CAD is challenging. Diagnostic tools such as electrocardiography (ECG), echocardiography, and cardiac biomarkers are of poor prognostic value in these special circumstances [11-15]. Consequentially, the European Association for Percutaneous Cardiovascular Interventions proposed to perform a short stop at the emergency department for diagnostic workup and to detect obvious non-coronary causes; all other patients should undergo CAG as soon as possible [16]. In the recent guidelines the European Society of Cardiology encouraged the catheterization of all SCA patients without persistent ST-segment elevation when they are in cardiogenic shock. For patients who are hemodynamically stable, a delayed CAG approach should be considered [10, 17].

Despite these recommendations, CAG as a standard treatment after SCA does not seem to be implemented extensively in daily clinical routine. A systematic meta-analysis of 11 studies found that only $41.5 \%$ of the patients without STE underwent emergent CAG [18].

Therefore, we report the rate of CAG in a tertiary care center and aim to identify the factors that influence the decision pro or contra CAG diagnostics.

\section{Patients, material and methods}

\section{Study setting}

Vienna, the capital of Austria, had approximately 1.77 million inhabitants during the study period. Treatment for out-of-hospital cardiac arrest is provided by the municipal ambulance service, as described elsewhere [19]. We screened patients who experienced in-hospital or out-of-hospital SCA and were treated at the Department of Emergency Medicine at the Vienna General Hospital and/or by a medical emergency team. The Vienna General Hospital is a tertiary care center at the Medical University of Vienna. At the Department of Emergency Medicine, approximately 280 cardiac arrests are treated every year.

\section{Selection for CAG}

Patient selection for CAG was performed by the attending physicians in the emergency department, intensive care units, or normal wards. During the study period, no standard operating procedures for the treatment of SCA without STE were established at our hospital. CAG \pm PCI was available 24/7 although the team was on call on weekday night shifts during the study period.

\section{Study design and time period}

We prospectively collected data of patients who received resuscitation or post-resuscitation care at our department after in-hospital and out-of-hospital cardiac arrest. Data collection, including outcome and prearrest conditions, was performed according to the Utstein criteria and stored in our local resuscitation database [20]. We screened this database for patients aged $\geq 18$ years with presumed cardiac cause of arrest and sustained return of spontaneous circulation from 1 January 2005, to 31 December 2014. Trained study fellows reviewed the first ECG after admission for signs of ischemia. Patients without STE at admission were included in further analysis.

All available CAG results during the hospital stay were collected. Based on the reports of interventional cardiologists, we stratified our collective into three groups: CAG, no occlusive CAD, CAG, occlusive CAD and no CAG examination. Lesions were deemed occlusive if any kind of intervention (PCI, thrombus aspiration, coronary artery bypass grafting, CABG) was indicated.

The rate and timing of CAG were defined as the primary endpoints. As secondary endpoints, the reasons pro and contra CAG were analyzed. Furthermore, we observed whether the criteria used for decision making occurred more often in patients with treatable CAD. Favorable neurological outcome, defined as cerebral performance categories (CPC) 1-2, was reported at day 30 after return of spontaneous circulation (ROSC). As the treatment of awake patients after cardiac arrest differs from that of comatose survivors, subgroup analyses for patients with a Glasgow Coma Scale (GCS) score $<8$ at admission were performed.

This study was a retrospective analysis of our resuscitation database and complied with the Declaration of Helsinki. This study was approved by the ethics committee of the Medical University of Vienna (EK 1814/2012 and 1485/2016).

\section{Data analysis}

Categorical data were expressed as counts followed by percentages ( $n \%$ ), and differences between groups were computed using a $\chi^{2}$-test. Interval-scaled measurements were expressed as median and interquartile range (IQR). In the absence of a normal distribution as per the Kolmogorov-Smirnov test, differences between groups were determined using the MannWhitney U test.

We performed binary logistic regression with an inclusion model with $95 \%$ CI with a $p$-value for entry of 0.05 and $p$-value for removal of 0.1. Statistical significance was set at $p<0.05$. All statistical analyses were performed using SPSS Statistics for MAC Version 24 and 25 (IBM, Armonk, NY, USA). 
Fig. 1 Study flowchart. SCA Sudden cardiac arrest, ROSC return of spontaneous circulation, STEMISTelevation myocardial infarction, CAG coronary angiography, $\mathrm{PCl}$ percutaneous coronary intervention, $C A B G$ coronary artery bypass grafting

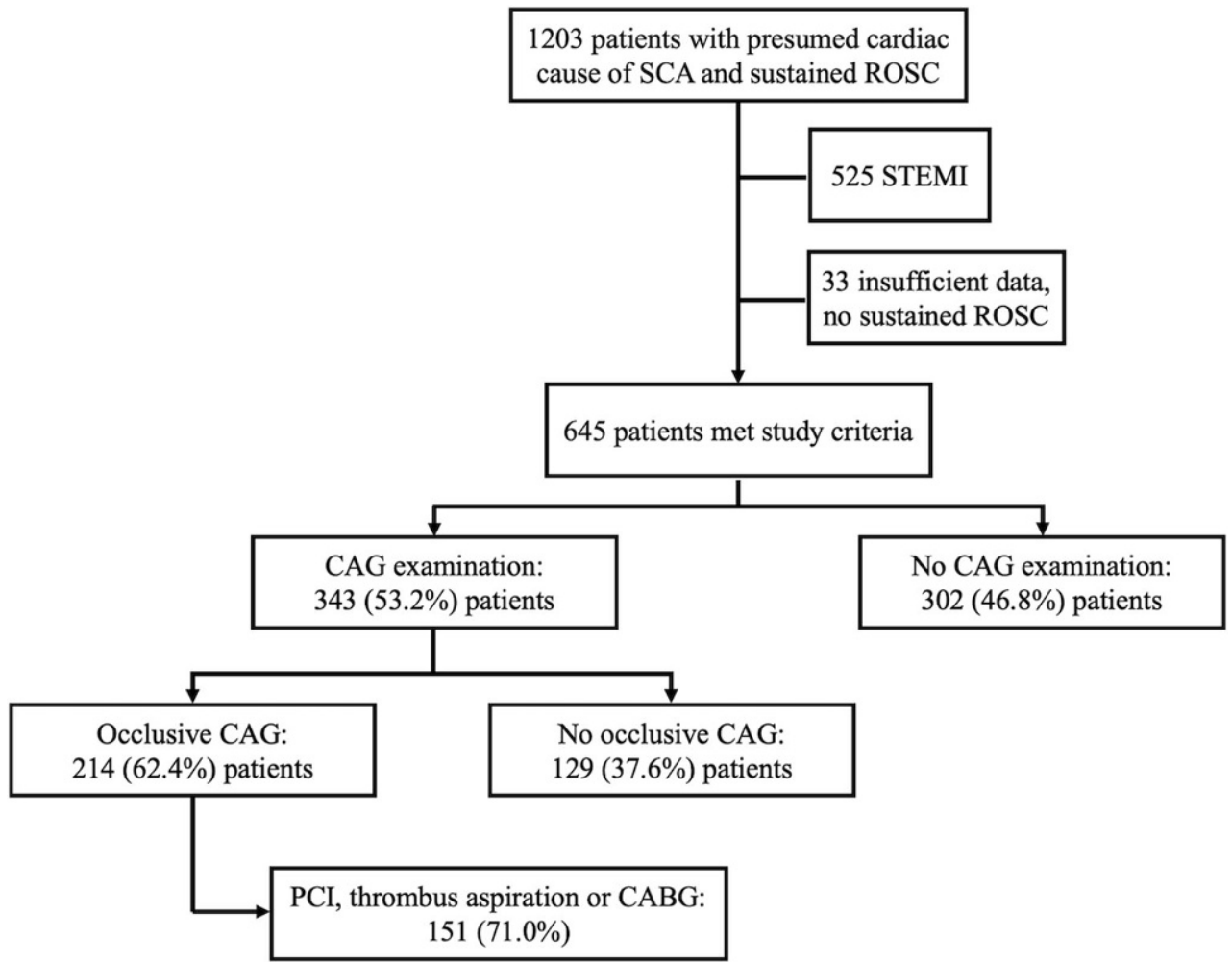

\section{Patient and public involvement}

Patients and the public were not involved in the design and conduction of this trial.

\section{Results}

During the study period, 645 (53.6\%) out of 1203 screened patients with presumed cardiac causes from our resuscitation database met the inclusion criteria (see Fig. 1). Baseline characteristics are shown in Table 1. A CAG was performed in $343(53.2 \%)$ patients with a subsequent diagnosis of occlusive CAD in $214(62.4 \%)$ patients; of these, in $151(71.0 \%)$ patients occlusive CAD was treated with PCI, thrombus aspiration or CABG (Fig. 1). PCI and/or thrombus aspiration was unsuccessful in $71(33.2 \%)$ patients $(8$ patients were subsequently treated with acute $C A B G$ ). After successful treatment, favorable neurological outcomes at 30 days were observed in $65.6 \%$ ( $n=99 / 151)$. Survival rates are presented in Table 1.

The CAG was performed on the day of admission in $180 / 645$ patients (27.9\%). On the second day, 40/576 (6.9\%, patients at risk: CAG: $n=330$, no $\mathrm{CAG}=246$ ) patients underwent CAG, whereas 117/562 (20.8\%, patients at risk: CAG: $n=327$, no CAG: $n=235$ ) patients were examined later during their stay (time for six patients not available) on median day 14 [8-21]. Survival with good neurological outcome for patients with GCS $<8$ at admission was $31.6 \%$ for patients with CAG on the day of admission, $40 \%$ for those with CAG on day 1 , and $67.5 \%$ for those with CAG later during hospital stay ( $p<0.001$ and $p=0.024$, respectively).

Data on cardiovascular risk factors were collected and compared between the groups. Patients with preexisting CAD, diabetes, hypertension, and cardiomyopathy were less often examined using CAG than those without these conditions (Table 1). We conducted binary logistic regression analysis to identify the factors influencing the decision to perform CAG (Table 2).

In a crude model, initially shockable rhythm, bystander CPR, witnessed arrest, male sex, current smoking, and hyperlipidemia were associated with high rates of CAG. After adjustment for all factors in Table 2, this effect persisted for shockable rhythm, male sex, and hyperlipidemia. In contrast, even after adjustment, age $\geq 70$ years, previously diagnosed $\mathrm{CAD}$, and cardiomyopathy were factors associated with lower rates of CAG.

In a binary logistic regression analysis of occlusive vs. non-occlusive CAD, initial shockable rhythm (OR 0.355 ; 95\% CI 0.192-0.657; $p<0.001)$, current smoking (OR 0.577; 95\%CI 0.346-0.962; $p=0.035$ ), and hypertension (OR 0.585; 95\% CI 0.358-0.956; $p=0.032$ ) were the only factors that were significantly associated with a high likelihood of occlusive CAD.

After adjustment for usual cofactors of outcome, the absence of occlusive CAD and shockable initial rhythm were predictive of good neurological survival after 30 days (Table 3). 
Table 1 Baseline characteristics

\begin{tabular}{|c|c|c|c|c|c|c|}
\hline & CAG $(n=343)$ & No CAG $(n=302)$ & $p$-value & $\begin{array}{l}\text { CAG—occlusive CAD } \\
(n=214)\end{array}$ & $\begin{array}{l}\text { CAG-no occlusive CAD } \\
(n=129)\end{array}$ & $p$-value \\
\hline Age, years, median [IQR] & 60 [51-68] & $70[59-79]$ & $<0.001$ & $60[52-68]$ & $59[48-69]$ & 0.253 \\
\hline Male sex, $n(\%)$ & $282(82.2)$ & $211(69.9)$ & $<0.001$ & $181(84.6)$ & $101(78.3)$ & 0.140 \\
\hline Body mass index, median [IQR] & $27.2[24.2-29.5]$ & $26.6[24.0-29.4]$ & 0.299 & $27.2[24.6-29.6]$ & $26.9[23.6-29.7]$ & 0.253 \\
\hline Initial shockable, $n(\%)$ & $273(79.6)$ & $148(49.0)$ & $<0.001$ & $181(84.6)$ & $92(71.3)$ & 0.003 \\
\hline Arrest witnessed, $n(\%)$ & $313(91.3)$ & $259(85.8)$ & 0.028 & $193(90.2)$ & $120(93.0)$ & 0.368 \\
\hline Bystander CPR, $n(\%)$ & $151(44.0)$ & $95(31.5)$ & 0.001 & $83(38.8)$ & $68(52.7)$ & 0.012 \\
\hline Time to ROSC, minutes, median [IQR] & $15[6-24]$ & 19 [7-33] & 0.007 & 15 [6-23] & $15[8-25]$ & 0.625 \\
\hline pH value at admission, median [IQR] & $7.24[7.14-7.31]$ & $7.20[7.08-7.29]$ & 0.006 & $7.23[7.14-7.31]$ & $7.25[7.16-7.32]$ & 0.520 \\
\hline $\begin{array}{l}\text { Lactate at admission (mmol/L), median } \\
\text { [lQR] }\end{array}$ & $5.9[3.6-8.0]$ & $7.2[4.2-10.4]$ & $<0.001$ & $6.1[3.7-8.2]$ & $5.5[3.6-7.8]$ & 0.535 \\
\hline $\begin{array}{l}\text { Troponin T at admission }(\mu \mathrm{g} / \mathrm{L}) \text {, median } \\
\text { [IQR] }\end{array}$ & $\begin{array}{l}0.048 \\
{[0.020-0.146]}\end{array}$ & $\begin{array}{l}0.060 \\
{[0.020-0.140]}\end{array}$ & 0.422 & $0.057[0.020-0.206]$ & $0.040[0.020-0.105]$ & 0.046 \\
\hline $\begin{array}{l}\text { proBNP at admission ( } \mathrm{pg} / \mathrm{mL}) \text {, median } \\
\text { [lQR] }\end{array}$ & $542[140-1798]$ & 2297 [611-6637] & $<0.001$ & 488 [128-1359] & 694 [157-2157] & 0.155 \\
\hline Creatinine (mg/dL), median [IQR] & $1.27[1.05-1.51]$ & $1.43[1.16-1.81]$ & $<0.001$ & $1.26[1.04-1.48]$ & $1.28[1.07-1.54]$ & 0.185 \\
\hline CPC 1 prior to CA, $n(\%)$ & $332(96.8)$ & $277(91.7)$ & 0.002 & $208(97.2)$ & $124(96.1)$ & 0.266 \\
\hline GCS < 8 at admission, $n(\%)$ & $260(75.8)$ & $248(82.1)$ & 0.122 & $157(73.4)$ & $103(79.8)$ & 0.139 \\
\hline $\begin{array}{l}\text { Targeted temperature management } \\
\left(33 \pm 1^{\circ} \mathrm{C}\right), n(\%)\end{array}$ & $246(71.7)$ & $205(67.9)$ & 0.289 & $144(67.3)$ & $102(79.1)$ & 0.019 \\
\hline \multicolumn{7}{|l|}{ Cardiovascular risk factors } \\
\hline Previous diagnosed CAD, $n(\%)$ & $118(34.4)$ & $141(46.7)$ & 0.001 & $82(38.3)$ & $36(27.9)$ & 0.049 \\
\hline Cardiomyopathy, $n(\%)$ & $53(15.5)$ & $109(36.1)$ & $<0.001$ & $24(11.2)$ & $29(22.5)$ & 0.005 \\
\hline Current smoking, $n(\%)$ & $123(35.9)$ & $62(20.5)$ & $<0.001$ & $91(42.5)$ & $32(24.8)$ & 0.001 \\
\hline Hyperlipidemia, $n(\%)$ & $126(36.7)$ & $52(17.2)$ & $<0.001$ & $87(40.7)$ & $39(30.2)$ & 0.052 \\
\hline Diabetes mellitus, $n(\%)$ & $74(21.6)$ & $99(32.8)$ & 0.001 & $53(24.8)$ & $21(16.3)$ & 0.064 \\
\hline Hypertension, $n(\%)$ & $163(47.5)$ & $169(56.0)$ & 0.032 & $111(51.9)$ & $52(40.3)$ & 0.038 \\
\hline \multicolumn{7}{|l|}{ 30-day survival } \\
\hline All patients, $n(\%)$ & $286(83.4)$ & $135(44.7)$ & $<0.001$ & $168(78.5)$ & $118(91.5)$ & 0.002 \\
\hline GCS < 8 at admission, $n(\%)$ & $189(55.1)$ & $74(24.5)$ & $<0.001$ & $104(48.6)$ & $85(65.9)$ & 0.002 \\
\hline \multicolumn{7}{|l|}{ 30-day survival (CPC1 + 2) } \\
\hline All patients, $n(\%)$ & $248(72.3)$ & $88(29.1)$ & $<0.001$ & $140(65.4)$ & $108(83.7)$ & $<0.001$ \\
\hline GCS < 8 at admission, $n(\%)$ & $157(45.8)$ & $36(11.9)$ & $<0.001$ & $81(37.9)$ & $76(58.9)$ & $<0.001$ \\
\hline Length of hospital stay in days & 24 [14-39] & 21 [8-51] & 0.298 & 24 [13-45] & $25[15-36]$ & 0.669 \\
\hline
\end{tabular}

In our study cohort, $152(23.6 \%)$ patients were women. The median age was 65.0 ([52.25-77.0]) years in women and 64.0 (53.0-73.0) years in men $(p=0.287)$. Female patients received CAG less often than male patients $(57.2 \%$ vs. $40.1 \%, p<0.001)$, resulting in an odds ratio of 1.99 (95\%CI, 1.38-2.89) for no CAD examination in female patients. We found no statistically significant difference in PCI rates between men $(41.8 \%)$ and women $(41.0 \%, p=0.902)$. There was no difference in the 30-day survival rate with CPC 1-2 between men $(53.6 \%)$ and women $(48.3 \%, p=0.261$, GCS <8: $46.4 \%$ vs. $42.1 \%, p=0.463)$. There was also no difference in the 30-day survival between men and women who underwent CAG $(86.5 \%$ vs. $87.8 \%$, $p=0.809)$ or were treated with occlusive CAD $(80 \%$ vs. $84.6 \%, p=0.584$ ). We analyzed all baseline characteristics, risk factors, and pre-existing conditions for intersexual differences. Table 4 presents all sta- tistically significant results, and none of the other parameters appear to be significant.

\section{Discussion}

In our retrospective analysis, we observed a CAG rate of $53.2 \%$ after the initially survived SCA. On the day of admission, CAG was performed in only about one quarter of all patients, although in those undergoing CAG, a subsequent diagnosis of occlusive CAD was frequent. We identified high age, female sex, nonshockable rhythms, and cardiomyopathy as factors associated with less CAG.

\section{Selection for coronary angiography}

Although CAG after SCA has become an established and safe therapy over the last few decades, the current 
Table 2 Factors favoring or withholding coronary angiography

\begin{tabular}{|c|c|c|c|c|c|c|}
\hline & Crude OR & $95 \% \mathrm{Cl}$ & $p$-value & Adjusted OR & $95 \% \mathrm{Cl}$ & $p$-value \\
\hline Age $\geq 70$ years & 3.535 & $2.520-4.960$ & $<0.001$ & 2.512 & $1.692-3.729$ & $<0.001$ \\
\hline Male sex & 0.502 & $0.346-0.726$ & $<0.001$ & 0.638 & $0.417-0.977$ & 0.039 \\
\hline Arrest witnessed & 0.577 & $0.352-0.947$ & 0.029 & 0.621 & $0.344-1.123$ & 0.115 \\
\hline Bystander CPR & 0.584 & $0.422-0.806$ & 0.001 & 0.947 & $0.629-1.427$ & 0.786 \\
\hline Initially shockable & 0.246 & $0.174-0.348$ & $<0.001$ & 0.334 & $0.223-0.502$ & $<0.001$ \\
\hline Previous diagnosed CAD & 1.670 & $1.216-2.294$ & 0.002 & 1.442 & $0.959-2.168$ & 0.079 \\
\hline Cardiomyopathy & 3.090 & $2.123-4.498$ & $<0.001$ & 2.274 & $1.484-3.484$ & $<0.001$ \\
\hline Current smoking & 0.462 & $0.324-0.660$ & $<0.001$ & 0.771 & $0.509-1.169$ & 0.221 \\
\hline Hyperlipidemia & 0.358 & $0.247-0.519$ & $<0.001$ & 0.337 & $0.218-0.521$ & $<0.001$ \\
\hline Diabetes mellitus & 1.773 & $1.247-2.521$ & 0.001 & 1.186 & $0.777-1.810$ & 0.430 \\
\hline Hypertension & 1.403 & $1.028-1.914$ & 0.033 & 1.031 & $0.707-1.505$ & 0.873 \\
\hline
\end{tabular}

Binary logistic regression analysis on factors favoring (odds ratio $<1$ ) or withholding CAG (odds ratio $>1$ ), OR odds ratio, $C /$ Confidence interval, $C P R$ cardiopulmonary resuscitation, $C A D$ coronary artery disease

Table 3 Predictive factors for good neurological function (CPC 1-2) after 30 days in patients after CAG

\begin{tabular}{|l|l|l|l|}
\hline Age, years & Adjusted OR & $95 \% \mathrm{Cl}$ & $p$-value \\
\hline Arrest witnessed & 0.988 & $0.968-1.009$ & 0.255 \\
\hline Bystander CPR & 1.959 & $0.838-4.576$ & 0.120 \\
\hline Initial shockable & 0.802 & $0.462-1.393$ & 0.434 \\
\hline No occlusive CAD & 2.188 & $1.148-4.170$ & $\mathbf{0 . 0 1 7}$ \\
\hline B. & 3.037 & $1.695-5.442$ & $<\mathbf{0 . 0 0 1}$ \\
\hline
\end{tabular}

Binary logistic regression analysis regarding good neurological outcome (CPC 1-2) after 30 days in patients who were examined with CAG, OR odds ratio, $C /$ confidence interval, $C P R$ cardiopulmonary resuscitation

Table 4 Intersexual differences

\begin{tabular}{|c|c|c|c|}
\hline & Female $(n=152)$ & Male $(n=493)$ & $p$-value \\
\hline Initially shockable, $n(\%)$ & $81(53.3)$ & $340(69.0)$ & $<0.001$ \\
\hline Known CAD, $n(\%)$ & $49(32.2)$ & $210(42.6)$ & 0.023 \\
\hline Cardiomyopathy, $n$ (\%) & $49(32.2)$ & $113(22.9)$ & 0.021 \\
\hline $\begin{array}{l}\text { proBNP at admission } \\
(\mathrm{pg} / \mathrm{mL}) \text {, median [IQR] }\end{array}$ & 1774 [382-5770] & 911 [214-2991] & 0.010 \\
\hline Hyperlipidemia, $n$ (\%) & $32(21.1)$ & $146(29.6)$ & 0.039 \\
\hline Smoking, $n(\%)$ & $26(17.1)$ & $159(32.3)$ & $<0.001$ \\
\hline $\mathrm{CPC} 1$ prior to $\mathrm{CA}, n(\%)^{\mathrm{a}}$ & $137(90.1)$ & $472(96.3)$ & 0.003 \\
\hline
\end{tabular}

resuscitation guidelines leave the choice of patient selection and time to perform a coronary catheter examination to the physician. In our center, this decision is made by the team in charge. During the study period, young patients received CAG frequently, whereas the intention to perform CAG for older patients was low. It is known that medical professionals tend to administer less aggressive treatment to patients of advanced age [21]. We hypothesized some of the rationales behind this decision: first, there is a strong commitment to treat young, yet healthy patients, with all the possible modalities like CAG, even if the probability of CAD is relatively low. Second, comorbidities and high age are known to be independent predictors of a poor outcome [21, 22]. This knowledge may contribute to the existence of a self-fulfilling prophecy, as little effort is made in post-resuscitation care of old and chronically ill patients $[23,24]$.

Lemkes et al. compared early and delayed CAG in resuscitated patients without STE [10]. Although early CAG was not associated with higher survival, patients with a history of $\mathrm{CAD}$ and $\geq 70$ years of age benefited from immediate CAG [25]. As a consequence, we arranged comparable subgroups for our regression analysis. Interestingly, high age was associated not only with delay but also with complete withholding of CAG in crude and adjusted models. As a result, patients with the highest risk of occlusive CAD did not receive CAG.

In our study population, cardiomyopathy was associated with few CAG examinations. We suppose that previous cardiac diseases are sometimes used to explain SCA as a result of fatal arrhythmias secondary to a previous myocardial scar, even if the probability of acute myocardial infarction as a trigger is high. In addition, pathological findings (e.g., wall motion abnormalities on echocardiography after ROSC) may be erroneously attributed to a pre-existing condition, thereby leading to the withholding of CAG.

Undoubtedly, all the factors mentioned above are associated with evolving difficulties during initial stabilization prior to CAG. In particular, patients with profound cardiogenic shock and insufficient response to vasoactive substances together with circumstances associated with poor neurological outcome (non-witnessed, no bystander CPR, non-shockable, long duration to ROSC) could have led to the decision to allow natural death. Of note, female sex was a predictor of non-administration of CAG. The same effect was observed in several other studies in Denmark, France, and the USA, although the underlying circumstances are not well understood [26-28].

In fact, shockable rhythms occurred less frequently, but cardiomyopathy was more often diagnosed in women than in men prior to cardiac arrest. It is pos- 
sible that unmeasured confounders (e.g., few rates of reported chest pain prior to the event) also influenced the decision against CAG; however, no significant differences were found between the sexes in the percentage of patients who underwent PCI or achieved good neurological survival after CAG. The comparable PCI rates between men and women found in our study are in line with those reported in previous studies, implying the same prevalence of occlusive CAD in both sexes $[27,28]$; however, the relevance of PCI in these patients remains unclear. While no difference in good neurological outcome was found in our data, Blom et al. reported lower survival rates among women than among men after cardiac arrest [29].

Perhaps CAG may be representative of an aggressive treatment bundle. Patients who were sent to CAG also received a high intensity of care concerning other modalities [6]. Consequentially, CAG could be an indication for aggressive postresuscitation care in younger patients. This selection bias also explains the remarkably high survival rates of patients without occlusive CAD. In these cases, CAG may have been performed despite lower pre-test probability (less cardiovascular risk factors, less shockable patients, lower troponin levels) just to make sure that everything possible has been done. This is also reflected by the use of targeted temperature management for almost every comatose patient in this group $(99 \%, n=102 / 103)$.

\section{Coronary lesions in patients without non-cardiac causes of arrest}

Dumas et al. performed CAG in all patients without STE, resulting in the diagnosis of at least 1 significant lesion in $58 \%$ of the cases [5]. The recently published COACT trial found clinically significant stenosis in two thirds of the patients [10]. Both numbers are consistent with our findings. Therefore, we assume that the rate of coronary lesions would be equally high in patients who do not undergo CAG examination.

After adjustment for confounders, our analyses revealed that only shockable initial rhythm, hypertension, and smoking were associated with a high probability of occlusive CAD. While shockable initial rhythm [5, 14, 30] and smoking [5, 7] were predictive of occlusive CAD in several other studies, data regarding hypertension are conflicting. Thus, in addition to the former two factors, it is hardly possible to identify patients with occlusive $\mathrm{CAD}$ based on their clinical parameters.

\section{Limitations}

This study has some important limitations. The main limitation is the lack of randomization due to the retrospective design. Therefore, we have to face a selection bias, which is inherent to all comparable studies concerning CAG after SCA. As mentioned, patients for CAG were selected at the discretion of the treating physicians. Thus, we were not able to estimate the influence of factors such as hemodynamic stability or availability of the catheterization laboratory on our findings.

Patients selected for CAG had more favorable parameters (e.g., initial shockable rhythms, younger age), which is consistent with other studies concerning this issue. It has to be considered that this could lead to falsely high survival rates [18, 31]. Another limitation is concerning the timing bias in our survival rates. If patients died early, namely in the first minutes or hours of the hospital stay and therefore never reached CAG, they are counted under "no CAG." On the other hand, patients who did not undergo CAG until neurological recovery would naturally live longer, resulting in this bias. Thus, we suppose that the reported survival rates were overestimated.

With respect to the presented rates of patients who received CAG, we assume another limitation: data about the coronary morphology of patients who died without CAG or who did not undergo CAD examination during the hospital stay are not available. The autopsy rates after SCA in our center are too low to report substantive pathological data regarding coronary morphologies. Nevertheless, considering the comparable prevalence data from the COACT trial in which almost all patients received CAG, it is likely that CAD would be equally frequent in the patients who were not examined.

The presented findings are based on an SCA population derived from an observational and descriptive registry. Inherent to all retrospective studies, the quality of the medical records limited this study. To mitigate these problems, data collection was meticulously and rigorously validated as part of a quality improvement review. Due to changes in the database, we were not able to include patients after 2014. As the selection criteria for CAG have not changed since then, we assume that the findings remain valid to date.

\section{Conclusion}

Although a selection bias was unavoidable due to the retrospective design of this study, a CAG rate of $53.2 \%$ with subsequent diagnosis of occlusive CAD in $62.4 \%$ of our SCA patients was found. The criteria used for patient selection may be suboptimal. For a conclusive answer about the correct timing, we urgently need more results from ongoing prospective clinical trials [32].

Acknowledgements We would like to thank Eva Fischer, MD for her linguistic proofreading and Gerhard Ruzicka for his excellent and indefatigable work as study coordinator.

Author Contribution MM and CW did the conceptualization. Data curation was performed by MM, DD, CR, CC, CS, AN, Mi.H and CW. Methodology was done by MM, MiH and MaH. The first draft was written by MM. All authors read, 
reviewed and revised the draft critically for important intellectual content and have approved the final version. CW was the supervisor of the project.

Funding Open access funding provided by Medical University of Vienna.

\section{Declarations}

Conflict of interest M. Mueller, D. Dziekan, M. Poppe, C. Clodi, C. Schriefl, M. Hofbauer, C. Roth, A. Nuernberger, M. Holzer and C. Weiser declare that they have no competing interests.

Ethical standards The ethics committee of the Medical University of Vienna (EK 1814/2012 and 1485/2016) approved this trial, with a waiver for informed consent.

Open Access This article is licensed under a Creative Commons Attribution 4.0 International License, which permits use, sharing, adaptation, distribution and reproduction in any medium or format, as long as you give appropriate credit to the original author(s) and the source, provide a link to the Creative Commons licence, and indicate if changes were made. The images or other third party material in this article are included in the article's Creative Commons licence, unless indicated otherwise in a credit line to the material. If material is not included in the article's Creative Commons licence and your intended use is not permitted by statutory regulation or exceeds the permitted use, you will need to obtain permission directly from the copyright holder. To view a copy of this licence, visit http://creativecommons.org/licenses/by/4.0/.

\section{References}

1. Berdowski J, Berg RA, Tijssen JGP, Koster RW. Global incidences of out-of-hospital cardiac arrest and survival rates: systematic review of 67 prospective studies. Resuscitation. 2010;81:1479-87. https://doi.org/10.1016/j.resuscitation. 2010.08.006.

2. Hayashi M, Shimizu W, Albert CM. The spectrum of epidemiology underlying sudden cardiac death. Circ Res. 2015;116:1887. https://doi.org/10.1161/CIRCRESAHA. 116.304521.

3. Nolan JP, Soar J, Cariou A, Cronberg T, Moulaert VRM, Deakin CD, et al. European resuscitation council and European society of intensive care medicine guidelines for post-resuscitation care 2015: section 5 of the European resuscitation council guidelines for resuscitation 2015 . Resuscitation. 2015;95:202-22. https://doi.org/10.1016/j. resuscitation.2015.07.018.

4. Nikolaou NI, Welsford M, Beygui F, Bossaert L, Ghaemmaghami C, Nonogi $\mathrm{H}$, et al. Part 5: Acute coronary syndromes: 2015 International Consensus on Cardiopulmonary Resuscitation and Emergency Cardiovascular Care Science with Treatment Recommendations. Resuscitation. 2015;95:e121-e46. https://doi.org/10.1016/j. resuscitation.2015.07.043.

5. Dumas F, Bougouin W, Geri G, Lamhaut L, Rosencher J, Pène F, et al. Emergency percutaneous coronary intervention in post-cardiac arrest patients without ST-segment elevation pattern: insights from the PROCAT II registry. JACC Cardiovasc Interv. 2016;9:1011-8. https:// doi.org/10. 1016/j.jcin.2016.02.001.

6. Hollenbeck RD, McPherson JA, Mooney MR, Unger BT, Patel NC, McMullan PW, et al. Early cardiac catheterization is associated with improved survival in comatose survivors of cardiac arrest without STEMI. Resuscitation.
2014;85:88-95. https://doi.org/10.1016/j.resuscitation. 2013.07.027.

7. WesterA, Mohammad MA,AndellP, RylanceR,DankiewiczJ, Friberg $\mathrm{H}$, et al. Coronary angiographic findings and outcomes in patients with sudden cardiac arrest without STelevationmyocardialinfarction: aSWEDEHEARTstudy. Resuscitation. 2018; https://doi.org/10.1016/j.resuscitation. 2018.01.044.

8. Dankiewicz J, Nielsen N, Annborn M, Cronberg T, Erlinge D, Gasche Y, et al. Survival in patients without acute ST elevation after cardiac arrest and association with early coronary angiography: a post hoc analysis from the TTM trial. Intensive Care Med. 2015;41:856-64. https://doi.org/ $10.1007 / \mathrm{s} 00134-015-3735-\mathrm{z}$.

9. Bro-Jeppesen J, Kjaergaard J, Wanscher M, Pedersen F, Holmvang L, Lippert FK, et al. Emergency coronary angiography in comatose cardiac arrest patients: do reallife experiences support the guidelines? Eur Heart J Acute Cardiovasc Care. 2012;1:291-301.https://doi.org/10.1177/ 2048872612465588.

10. Lemkes JS, Janssens GN, van der Hoeven NW, Jewbali LSD, Dubois EA, Meuwissen M, et al. Coronary angiography after cardiac arrest without ST-segment elevation. NEngl J Med. 2019;380:1397-407.https://doi.org/10.1056/ NEJMoa1816897.

11. Cha K-C, Kim HI, Kim OH, Cha YS, Kim H, Lee KH, et al. Echocardiographic patterns of postresuscitation myocardial dysfunction. Resuscitation. 2018;124:90-5. https:// doi.org/10.1016/j.resuscitation.2018.01.019.

12. Spaulding CM, Joly LM, Rosenberg A, Monchi M, Weber SN, Dhainaut JF, et al. Immediate coronary angiography in survivors of out-of-hospital cardiac arrest. N Engl J Med. 1997;336:1629-33. https://doi.org/10.1056/ NEJM199706053362302.

13. Pearson DA, Wares CM, Mayer KA, Runyon MS, StudnekJR, Ward SL, et al. Troponin marker for acute coronary occlusion and patient outcome following cardiac arrest. West J Emerg Med. 2015;16:1007-13. https://doi.org/10.5811/ westjem.2015.10.28346.

14. Aurore A, Jabre P, Liot P, Margenet A, Lecarpentier E, Combes X. Predictive factors for positive coronary angiography in out-of-hospital cardiac arrest patients. Eur J Emerg Med. 2011;18:73-6. https://doi.org/10.1097/MEJ. 0b013e32833d469a.

15. Geri G, Mongardon N, Dumas F, Chenevier-Gobeaux C, Varenne O, Jouven X, et al. Diagnosis performance of high sensitivity troponin assay in out-of-hospital cardiac arrest patients. Int J Cardiol. 2013;169:449-54. https://doi.org/ 10.1016/j.ijcard.2013.10.011.

16. Noc M, Fajadet J, Lassen JF, Kala P, MacCarthy P, Olivecrona GK, et al. Invasive coronary treatment strategies for out-of-hospital cardiac arrest: a consensus statement from the European association for percutaneous cardiovascular interventions (EAPCI)/stent for life (SFL) groups. EuroIntervention. 2014;10:31-7. https://doi.org/10.4244/ EIJV10I1A7.

17. Collet J-P, Thiele H, Barbato E, Barthélémy O, Bauersachs J, Bhatt DL, et al. 2020 ESC Guidelines for the management of acute coronary syndromes in patients presenting without persistentST-segment elevation. Eur Heart J. 2020; https:// doi.org/10.1093/eurheartj/ehaa575.

18. Millin MG, Comer AC, Nable JV, Johnston PV, Lawner BJ, Woltman N, et al. Patients without ST elevation after return of spontaneous circulation may benefit from emergent percutaneous intervention: a systematic review and metaanalysis. Resuscitation. 2016;108:54-60. https://doi.org/ 10.1016/j.resuscitation.2016.09.004. 
19. Nürnberger A, Sterz F, Malzer R, Warenits A, Girsa M, Stöckl M, et al. Out of hospital cardiac arrest in Vienna: incidence and outcome. Resuscitation. 2013;84:42-7. https://doi.org/10.1016/j.resuscitation.2012.07.002.

20. Perkins GD, Jacobs IG, Nadkarni VM, Berg RA, Bhanji F, Biarent D, et al. Cardiac arrest and cardiopulmonary resuscitation outcome reports: update of the Utstein resuscitation registry templates for out-of-hospital cardiac arrest. Resuscitation. 2015;96:328-40. https://doi.org/10. 1016/j.resuscitation.2014.11.002.

21. Hirlekar G, Karlsson T, Aune S, Ravn-Fischer A, Albertsson P, Herlitz J, et al. Survival and neurological outcome in the elderly after in-hospital cardiac arrest. Resuscitation. 2017;118:101-6. https://doi.org/10.1016/j.resuscitation. 2017.07.013.

22. Sulzgruber P, Sterz F, Poppe M, Schober A, Lobmeyr E, Datler P, et al. Age-specific prognostication after out-ofhospital cardiac arrest- the ethical dilemma between "lifesustaining treatment" and "the right to die" in the elderly. Eur Heart J Acute Cardiovasc Care. 2017;6:112-20. https:// doi.org/10.1177/2048872616672076.

23. Kirkegaard H, Taccone FS, Skrifvars M, Søreide E. Postresuscitation care after out-of-hospital cardiac arrest: clinical update and focus on targeted temperature management. Anesthesiology. 2019; https://doi.org/10.1097/ALN. 0000000000002700.

24. Wilkinson D. The self-fulfilling prophecy in intensive care. Theor Med Bioeth. 2009;30:401-10. https://doi.org/10. 1007/s11017-009-9120-6.

25. Lemkes JS, Janssens GN, van der Hoeven NW, Jewbali LSD, Dubois EA, Meuwissen M, et al. Supplement to: coronary angiography after cardiac arrest without ST-segment elevation. N Engl J Med. 2019; https://doi.org/10.1056/ NEJMoa1816897.

26. Bosson N, KajiAH, FangA, ThomasJL, FrenchWJ, ShavelleD, etal. Sexdifferencesin survival from out-of-hospital cardiac arrest in the era of regionalized systems and advanced post- resuscitation care. JAm Heart Assoc. 2016; https:// doi.org/ 10.1161/JAHA.116.004131.

27. Bougouin W, Dumas F, Marijon E, Geri G, Champigneulle B, Chiche J-D, et al. Gender differences in early invasive strategy after cardiac arrest: Insights from the PROCAT registry. Resuscitation. 2017;114:7-13. https://doi.org/10. 1016/j.resuscitation.2017.02.005.

28. Winther-Jensen M, Hassager C, Kjaergaard J, Bro-Jeppesen J, Thomsen JH, Lippert FK, et al. Women have a worse prognosis and undergo fewer coronary angiographies after out-of-hospital cardiac arrest than men. Eur Heart J Acute Cardiovasc Care. 2017; https://doi.org/10.1177/ 2048872617696368.

29. Blom MT, Oving I, Berdowski J, van Valkengoed IGM, Bardai A, Tan HL. Women have lower chances than men to be resuscitated and survive out-of-hospital cardiac arrest. Eur Heart J. 2019;40:3824-34. https://doi.org/10.1093/ eurheartj/ehz297.

30. Vadeboncoeur TF, Chikani V, Hu C, Spaite DW, Bobrow BJ. Association between coronary angiography with or without percutaneous coronary intervention and outcomes after out-of-hospital cardiac arrest. Resuscitation. 2018; https:// doi.org/10.1016/j.resuscitation.2018.03.023.

31. Larsen JM, Ravkilde J. Acute coronary angiography in patients resuscitated from out-of-hospital cardiac arrest-a systematic review and meta-analysis. Resuscitation. 2012;83:1427-33. https://doi.org/10.1016/j.resuscitation. 2012.08.337.

32. Patterson T, Perkins GD, Joseph J, Wilson K, Dyck LV, Robertson S, et al. A Randomised tRial of Expedited transfer to a cardiac arrest centre for non-ST elevation ventricular fibrillation out-of-hospital cardiac arrest: TheARRESTpilot randomised trial. Resuscitation. 2017;115:185-91. https:// doi.org/10.1016/j.resuscitation.2017.01.020.

Publisher's Note Springer Nature remains neutral with regard to jurisdictional claims in published maps and institutional affiliations. 